\title{
ASSISTÊNCIA À CRIANÇA COM DISFUNÇÃO NEUROMOTORA NA ABORDAGEM DA REDE SOCIAL: UM ESTUDO DE CASO
}

\author{
Assistance to the child with neuromotor disorder using a social \\ networkapproach: A Case Study \\ Asistencia al niño con disfunción neuromotora en el abordaje de la \\ red social: Un estudio de caso.
}

\begin{abstract}
RESUMO
0 estudo de caso teve como propósito descrever a situação de saúde de uma criança com disfunção neuromotora e sua rede social, com aprofundamento no contexto socioeconômico. Os objetivos foram: identificar o cuidador da criança; construir o mapa da rede social da criança; discutir a importância do cuidador e contexto familiar no desenvolvimento da criança com disfunção neuromotora. Os dados foram coletados no prontuário na consulta de enfermagem; na abordagem da mãe durante a fisioterapia; na visita à casa da avó materna; na observação sistemática da criança, e mantiveram-se contatos pelo telefone. Os resultados mostraram que a menina está envolvida com diferentes pessoas e tem variados vínculos. Conclui-se que, apesar de a rede social ser ampla e densa, seus vínculos são fragilizados, o que torna a relação íntima e direta da menina restrita a poucas pessoas, como mãe, irmão e avó materna.
\end{abstract}

Palavras-chave: Reabilitação. Enfermagem. Paralisia Cerebral.

\begin{abstract}
The case study's intention was to describe the situation regarding the health of a child with neuromotor disorder and their social network, with deepening on socio-economic context. The objectives were: to identify the caretaker of the child; to build the map of the child's social network; to discuss the importance of the caretaker and family context in the development of the children with neuromotor disorder. The data were collected from the patient's record; consultation of nursing; approach of the mother during physiotherapy; visitation to the maternal grandmother's home; systematic observation of the child and contacts by phone. The results showed that the girl is involved with different people and different ties. It follows that despite her extensive and dense social network, her ties are fragile, which makes the direct and intimate relationship to the girl restricted to few people, such as her mother, her brother, her maternal grandmother.
\end{abstract}

\section{Resumen}

El estudio de caso tuvo como propósito describir la situación de la salud de una niña con disfunción neuromotora y su red social, con profundización en el contexto socio-económico. Los objetivos fueron: identificar el cuidador de la niña; construir el mapa de la red social de la niña; discutir la importancia del cuidador y del contexto familiar en el desarrollo de la niña con disfunción neuromotora. Los datos fueron colectados en el registro médico; consulta de enfermería; abordaje de la madre durante la fisioterapia; visita a la casa de la abuela materna; observación sistemática de la niña y contactos por teléfono. Los resultados mostraron que la niña está enredada con diversas personas y variados enlaces. Se concluye aunque la red social sea amplia y densa, sus enlaces son fragilizados, lo que torna la relación íntima y directa a la niña restricta a pocas personas, como madre, hermano, abuela materna. 


\section{INTRODUCÃO}

Este estudo de caso teve como propósito descrever a situação de saúde de uma criança com disfunção neuromotora e sua rede social com aprofundamento no contexto sócioeconômico.

A equipe multiprofissional atua como supor te terapêutico, mas cabe a família/cuidador a responsabilidade maior do diadia. Neste contexto, é preciso que a rede social da criança esteja de acordo com suas necessidades, e, neste momento, a enfermagem entra investigando a rede, para possíveis adaptações, orientações e encaminhamentos, favorecendo assim, uma melhor qualidade de vida pra esta criança.

A enfermagem, ao atuar considerando a rede social, deve estar atenta a todos os fatores que englobam não só a criança, mas também ao cuidador/família. Deve-se atentar para gestos, tom de voz e silêncio, assim há a possibilidade de detectar sinais que precisam de maior atenção. A escuta sensível deve ser enfatizada e reforçada, tendo em vista que estes fatores também carregam o significado das relações sociais.

A construção do mapa nos permite melhores resultados quando se quer conhecer detalhadamente o contexto social que o cliente está inserido, uma vez que a rede social é formada por pessoas que estão envolvidas na solução do problema em questão. É importante ressaltar que a rede não atua apenas no problema, mas também nos momentos de comemorações. Nessas ocasiões, além das questões práticas a serem resolvidas, entram em cena o apoio emocional, compaixão, ombro amigo, o acolhimento para maior conforto, reabilitação, ajuda material, lugares que o cliente frequenta (igreja, hospital, por exemplo), serviços e informaç̧ões'.

A rede social auxilia no estímulo do desenvolvimento da criança na sua identidade individual e coletiva. É por isso que, através da rede social, destaca-se o cuidador, pois este desempenha um papel fundamental na socialização, determinando valores e critérios que orientam a conduta individual, o desenvolvimento e a reabilitação da criança. Quando o cuidador e/ou a família encontram-se fragilizados, a tendência ao aumento das complicações e dificuldades de saúde da criança pode ser potencializada.

A família precisa receber informações a respeito do crescimento e desenvolvimento normal da criança, para que, a partir destas, possam distinguir o que é normal do anormal e, com isso, auxiliar no diagnóstico precoce de uma disfunção neuromotora. 0 principal elemento para o diagnóstico da disfunção neuromotora é a observação feita pelos pais/família, que reconhecem atrasos no desenvolvimento dos seus filhos, muitas vezes antes e melhor do que qualquer especialista ${ }^{2}$.

0 vínculo mãe/cuidador e filho propiciam um compromisso emocional com a criança, o qual pode ser a força fundamental que estimule a mãe/cuidador a cuidar do filho, uma vez que essa é a pessoa mais significativa e próxima, e através desse vínculo, ela absorve todos os problemas que acometem a criança nesse momento?
Dentre os fatores potencialmente determinantes de lesão cerebral irreversível, os mais comumente observados são infecções do sistema nervoso, hipoxia e traumatismo craniano. 0 desenvolvimento anormal do cérebro pode também estar relacionado com uma desordem genética, e, nestas circunstâncias geralmente se observam outras alterações primárias além da cerebral. Em muitas crianças, a lesão ocorre nos primeiros meses de gestação, e a causa é desconhecida ${ }^{3}$.

A criança estudada nasceu com agenesia parcial de corpo caloso com preservação do "rostrum" associada a onfalocele e lábio leporino. Esta malformação ocorre em 1 a 3 em 1.000 nascimentos. Ressalta-se que é comum a malformação isolada, no entanto encontra-se muitas vezes associada a cerca de 25 síndromes genéticas, erros inatos de metabolismo, uso de drogas lícitas (abuso de álcool) e ilícitas (cocaína) ${ }^{4}$. Em casos em que a agenesia do corpo caloso se apresenta isoladamente, a criança pode não apresentar alteraç̃̃es neurológicas, o que éraro ${ }^{5}$.

0 termo agenesia de corpo caloso significa uma malformação com origem na embriogênese do telencéfalo, de origem desconhecida ${ }^{6}$. Este é um conceito aplicado a diversos graus de malformação, ou seja, desde a ausência total até a mínima deficiência no seu desenvolvimento. Por isso, podemse classificar as desordens relacionadas à formação do corpo caloso em: a agenesia total, em que o corpo caloso está completamente ausente; parcial ou hipogenesia, na qual o corpo caloso apresenta graus variados de encurtamento; e a hipoplasia, quando o corpo caloso está formado, mas apresenta redução de seu tamanho, que pode ser focal ou difusa ${ }^{5}$.

Sabe-se que a onfalocele é um defeito na parede abdominal na inserção do cordão umbilical, com herniação de órgãos abdominais. Apresenta uma incidência de 2,5 em 10.000 nascidos vivos. Seu quadro é caracterizado pela ausência dos músculos abdominais, fáscia e pele, e, coberto por uma membrana avascular, forma uma hérnia. A migração das alças intestinais no cordão umbilical ocorre normalmente entre $8 \mathrm{e}$ 12 semanas de gestação, e a falha no retorno das alças intestinais para a cavidade abdominal resulta na formação de onfalocele. A embriogênese da onfalocele não é muito bem entendida ${ }^{3}$.

Já o lábio leporino é caracterizado pela malformação da face, que, pelo crescimento, surge da união de dois processos bilaterais separados: maxilares e mandibulares, e um fronto nasal, originando assim os processos nasais mediais e laterais. As fissuras resultam da falta de coalescência desses processos? ${ }^{7}$.

As fissuras de lábio e/ou palato são consideradas malformações congênitas de elevada incidência, atribuídas a fatores genéticos e ambientais, que podem atuar isolados ou em associação. Dentre os fatores ambientais, destacam-se os nutricionais, infecciosos, psíquicos, radiação, idade da mãe, uso de drogas e outros agentes químicos. A hereditariedade é responsável por $25 \%$ a $30 \%$ dos casos de fissuras de lábio e/ ou palato, e cerca de $70 \%$ a $80 \%$ dos casos são considerados

\footnotetext{
Rostrum significa rostro, que é uma parte do corpo caloso.
} 
de etiologia multifatorial. São consideradas a segunda malformação mais comum na população ${ }^{7}$

Para alcançar o propósito do estudo, foram traçados os seguintes objetivos: identificar o cuidador da criança; construir o mapa da rede social da criança; discutir a importância do cuidador e contexto familiar no desenvolvimento da criança com disfunção neuromotora.

\section{MÉTODOS}

0 caminho percorrido para a realização do estudo iniciou após a Aprovação do Comitê de Ética e Pesquisa da EEAN/ HESFA, com protocolo $n^{0}$ 066/07, e utilizou como fontes de evidências: leitura do prontuário; a consulta de enfermagem realizada no Hospital Escola São Francisco de Assis- HESFA da Universidade Federal do Rio de Janeiro/UFRJ; abordagem da mãe da criança enquanto a mesma se encontrava nas sessões de fisioterapia; a visita domiciliar na casa da avó materna, pois é o local onde passa a maior parte do tempo; observação sistemática, como complementação do estudo, orientada por um instrumento existente na consulta de enfermagem e contatos pelo telefone com a mãe e a avó da criança durante o período de um ano.

Para a construção do Mapa da Rede Social foi utilizada a metodologia proposta por Maria Luisa Pereira Ventura Soares ${ }^{1}$, autora de um livro que nasceu de experiências de assistentes sociais no Centro de Recuperação e Educação Nutricional (CREN), onde busca oferecer indicações e exemplos de métodos de trabalho que outros profissionais possam aplicar da melhor forma à realidade.

\section{RESULTADOS}

0 contato inicial se deu no ambulatório do HESFA por ocasião da primeira sessão de fisioterapia, além do histórico descrito pela fisioterapeuta, no qual foram percebidas a condição física e a necessidade de se aprofundar sobre a história de vida e, principalmente, sobre a constituição da rede social.

Iniciou-se a abordagem informalmente com a mãe em conversa a respeito da condição de saúde atual da criança, e, a partir disso, a interação foi iniciada até o agendamento da consulta de enfermagem, que ocorreu no dia 3 de maio de 2007.

A coleta de dados foi feita através da utilização de um instrumento próprio de consulta de enfermagem a crianças com disfunção neuromotora, com a identificação, informações gerais da criança, histórico da criança, histórico das doenças anteriores, exame físico, condições habituais de vida e plano de cuidados.

\section{Histórico Biopsicossocial}

Criança (A.L.G.C.P.) do sexo feminino, 3 anos, cor branca, cabelos castanhos claros, emagrecida $(6,345 \mathrm{~kg})$, baixa estatura $(73 \mathrm{~cm})$; perímetro cefálico: $40,5 \mathrm{~cm}$, perímetro torácico: $43,0 \mathrm{~cm}$; perímetro abdominal: $40,0 \mathrm{~cm}$. Nascida em 02/12/2003 numa maternidade X em Madureira, Rio de Janeiro. Reside com a mãe e o pai em casa alugada localizada no bairro de Bangu, Município do Rio de Janeiro. Sua mãe P.G.R, de 25 anos, solteira, "do lar", $2^{\circ}$ grau incompleto, católica e sem hábitos nocivos.

A mãe relata que não trabalha, pois cuida da criança em tempo integral. Refere ainda que a criança tem maior afinidade a ela e também não tem com quem deixá-la, pois não confia. $A$ única pessoa com quem deixaria é sua mãe, porém esta precisa dispor de toda atenção ao seu irmão (tio da criança) de 20 anos, também portador de disfunção neuromotora, ainda sem diagnóstico definido.

Apesar de passar o tempo todo com a mãe, elas nem sempre permanecem em Bangu. Sempre que a criança tem alguma consulta, elas retornam para a casa da avó em Rocha Miranda, devido à proximidade dos hospitais. A mãe relata agir dessa forma, pois elas precisam pegar conduções como ônibus e trem, com isso a menina fica muito agitada.

A criança tem ótimo relacionamento com a mãe, avó materna e irmão. E, segundo a mãe, a relação com o pai, a tia e o tio materno também é positiva. F.C.P., pai da criança, tem 23 anos, é solteiro, católico, etilista, com $1^{\circ}$ grau incompleto, e atua como auxiliar de serviços gerais no turno da noite.

A família vive da renda do pai da criança, do INSS desta e da ajuda da família Desta forma somam uma renda de aproximadamente 3 salários mínimos. A família tem um gasto mensal de $R \$ 150,00$ na assistência à saúde da menina. A Lei n 7853 de 24/10/1989, Art. $2^{\circ}$ - Parágrafo II, aborda uma questão relevante à ética profissional no tratamento de indivíduos portadores de deficiência, visto que trata sobre a garantia ao acesso destes a estabelecimentos de saúde para início e continuidade de tratamento; a garantia às pessoas portadoras de deficiência das ações governamentais necessárias ao pleno exercício de seus direitos básicos, inclusive dos direitos à educação, à saúde, ao trabalho, ao lazer, à previdência social, ao amparo, à infância e à maternidade, e de outras que, decorrentes da Constituição e das leis, propiciem seu bemestar pessoal, social e econômico, afastadas as discriminações e os preconceitos de qualquer espécie. Desta forma, nota-se que a criança, de acordo com a idade, goza dos direitos que lhe são oferecidos legalmente ${ }^{8}$.

Aos 21 anos, logo após o término do namoro, P.G.R descobre a gravidez não planejada e indesejada, já com quase 2 meses. Com isso reatam a relação. Acredita que engravidou por falta de cuidado e esqueceu de tomar o anticoncepcional por um dia. Para ela, foi um período conturbado, pois ambos estavam desempregados e dependiam integralmente das famílias.

Ao anunciar a gravidez, os familiares do namorado mostraram-se contra. Porém o pai da menina em momento algum hesitou em assumir a gravidez. Em todos os momentos de angústia e desespero de P.G.R., o pai da criança esteve presente apoiando e em nenhuma ocasião permitiu o aborto, 
que ela desejava, mas não teve coragem de realizar, mesmo recebendo "dicas" de amigos e vizinhos. P.G.R. também é mãe de um menino de 6 anos, nascido de parto normal e com crescimento e desenvolvimento normal.

Após todo o momento de negação da gravidez, P.G.R. procurou uma consulta pré-natal numa maternidade W no Lins de Vasconcelos, Rio de Janeiro, porém só conseguiu uma vaga com 3 meses de gestação. A mãe não fez uso, porém sempre manteve contato com o pai da menina, etilista e fumante.

Com relação ao percurso da gravidez, P.G.R. lembra que em todo instante se aborreceu. Referiu que durante toda a gestação sentia dores no baixo ventre e percebia que, em comparação à gravidez anterior, não teve os mesmos sintomas apresentados na da menina. Fez uso de antiespasmódico prescrito por médicos para alívio das dores abdominais.

No sétimo mês de gravidez, ainda com fortes dores no baixo ventre e um leve sangramento de coloração vermelhovivo, recorreu ao posto de saúde perto de sua residência onde foi feita uma ultrassonografia, que, segundo o médico, não apresentava anormalidades. No dia 04/11/2003, realizou sua última consulta pré-natal.

No dia 02/12/2003, com 39 semanas e 2 dias, P.G.R., entra em trabalho de parto, que durou, no total, 4 horas e 57 minutos, sendo 1 hora e 27 minutos de parto assistido (cesárea).

A criança nasceu às $14 \mathrm{~h} 57$ min com 39 semanas e 2 dias de gestação, com 1,860 gramas, pequena para idade gestacional (PIG), $42 \mathrm{~cm}$ de estatura e índice Apgar 08/09. 0 índice Apgar é útil para avaliar as condições de um recém-nato e orientar as medidas a serem tomadas; neste caso, pode-se classificar como sem asfixia e um índice bom ${ }^{3}$.

Além disso, o líquido amniótico apresentou-se com coloração de tinta de mecônio. A mãe relata que a menina não chorou, nasceu cianótica, e lembra que seu "rosto estava aberto" e o intestino "para fora"; após ver a menina nessa situação desmaiou. Às 16h30min, a menina foi encaminhada para cirurgia de emergência da onfalocele, a fim de evitar a infecção e o ressecamento do órgão.

Segundo informações colhidas no arquivo morto da maternidade $X$, a criança ficou internada durante um mês na Unidade de Terapia Intensiva Y, sobre suporte ventilatório. Após sua alta neste setor, foi transferida para o Hospital Z, onde ficou internada para aprender a mamar e ganhar peso por aproximadamente 20 dias. A mãe refere que tinha bastante leite, porém o hospital que ela estava não possuía banco de leite, e, como a menina estava internada em outro hospital, 0 leite "secou", não podendo assim, amamentar.

Segundo informações do prontuário do Hospital Escola São Francisco de Assis, com aproximadamente 2 anos e 6 meses, a mãe percebeu que a criança não desenvolvia o aspecto motor, cognitivo, e não crescia e nem ganhava peso, mantinha 0 tamanho de um recém-nato. Com isso recorreu ao pediatra, que a encaminhou para o neurologista, que deu o diagnóstico final da agenesia de corpo caloso.
Em abril de 2006, realizou a cirurgia para correção de Lábio Leporino no Hospital Y. A princípio, houve rejeição à cirurgia, porém não foi preciso realizar uma nova.

Ainda com dados colhidos no prontuário do HESFA, a fisioterapia avaliou a menina com quadriplegia atáxica manifestada por hipotonia com extensões, estereotipia, lentidão de movimentos, sem reação de proteção e aumento do tônus em membros inferiores.

Atualmente, A.L.G.C.P. está com 3 anos, porém com desenvolvimento e comportamento de um recém-nato, isto confirmado após a avaliação de posturas e reflexos. A mãe apresenta como queixa principal com relação à menina a constipação, o que a deixa sem eliminação intestinal por até 20 dias (SIC). Quando desta condição, apresenta-se agitada, às vezes febril, com abdome distentido e endurecido; porém, durante, a palpação superficial, não manifesta dor. A mãe foi orientada a realizar massagem abdominal, aumentar a ingesta hídrica e oferecer uma alimentação rica em frutas, vegetais e legumes.

\section{Visita Domiciliar}

Foi agendada e explicada a visita domiciliar à casa da avó materna de acordo com a disponibilidade da família. Cabe ressaltar que, para acompanhar a situação de saúde da menina, foi mantido o contato semanal através de telefone fornecido pela família.

A visita domiciliar ocorreu na tarde do dia 22 de maio de 2007, em Rocha Miranda. Chegamos até o local por viatura do HESFA, solicitada previamente. Fomos recebidos com muito carinho e atenção, o que favoreceu o nosso encontro. Procuramos manter uma postura livre de qualquer julgamento, acolhendo com escuta sensivel e atenção, o que nos permitiu estabelecer vínculo que se aprofundou em confiança.

A casa era simples, bem apresentada e com bom padrão de higiene. Um imóvel alugado com quatro cômodos (sala, quarto, cozinha, banheiro) e quintal. A sala tinha boa ventilação, com iluminação natural e artificial. 0 quarto, abafado, com uma cama de casal e uma de solteiro, e a cozinha não tinham ventilação e iluminação natural, apenas artificial (ausência de janela). A cama de casal é o local onde a menina fica deitada durante o período que está na avó.

Antes de abordar a família para construir a rede social da criança e realizar o exame físico, conversamos com a mãe da menina a respeito da Aprovação do Comitê de Ética e Pesquisa e apresentamos o Termo de Consentimento Livre e Esclarecido de acordo com a Resolução 196/96 do Conselho Nacional de Saúde - Item IV, tratando em especial o respeito do sigilo e anonimato dos sujeitos. Foi esclarecido à mãe que ela tinha 0 direito de não querer participar do estudo se assim o desejasse. Após consentimento, foi feito o registro fotográfico da menina nas principais posições de avaliação da criança.

Na casa estava o bisavô da menina, a avó, o tio, o irmão e a mãe. A menina estava deitava na cama da avó. Ao encontrá- 
la, pôde-se perceber a serenidade, calma e tranquilidade, sem a agitação constante das sessões de fisioterapia.

No primeiro momento, abordou-se a mãe para saber a respeito da situação de saúde atual da menina. A primeira queixa da mãe foi a constipação intestinal apresentada, a qual mantivemos as orientações citadas. No segundo momento, realizou-se o exame físico, com enfoque nas posturas, na região abdominal e sinais vitais, que apresentava temperatura axilar de $36,2^{\circ} \mathrm{C}$, frequência apical de $104 \mathrm{bpm}$ e frequência respiratória de 24 irpm. Quanto à inspeção, não foi percebida nenhuma anormalidade.

Na avaliação observou-se:

Posição Supina: é capaz de manter a cabeça na linha mediana com predomínio flexor; esperneios simultâneos; movimentos maciços e numerosos; mãos em linha média (boca); puxa os cabelos, principalmente em momentos de manipulação; toca o corpo; pega os pés; acompanha objetos com ângulo de $180^{\circ}$; não tenta sentar e engatinhar.

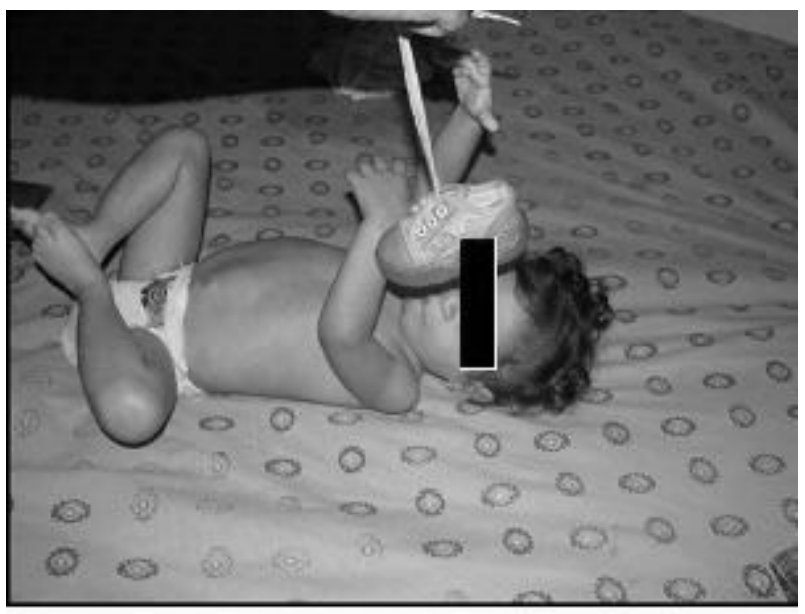

Fig: 01 - Posição Supina

Posição Prona: eleva a cabeça por pouco tempo; não retrai os ombros na tentativa de se levantar, não eleva o quadril; libera as vias aéreas com predomínio da transferência para o lado direito; não possui controle da cabeça, tem predomínio de hiperextensão de cabeça.

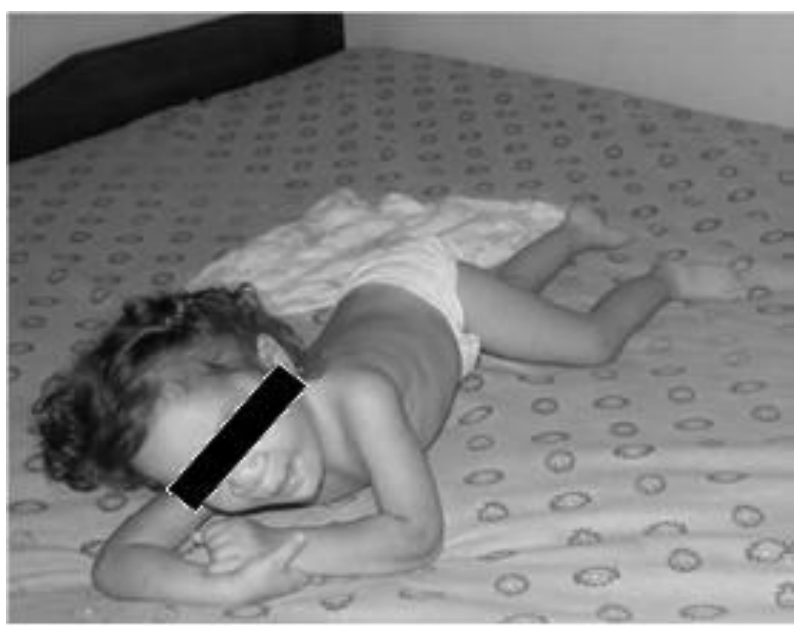

Fig: 02- Posição Prona
Posição de Decúbito Lateral: ao ser colocada nessa posição, muda rapidamente para posição supina. Não mantém cabeça e braços na linha mediana; não retifica lateralmente a cabeça e não possui equilíbrio muscular abdominal e dorsal.

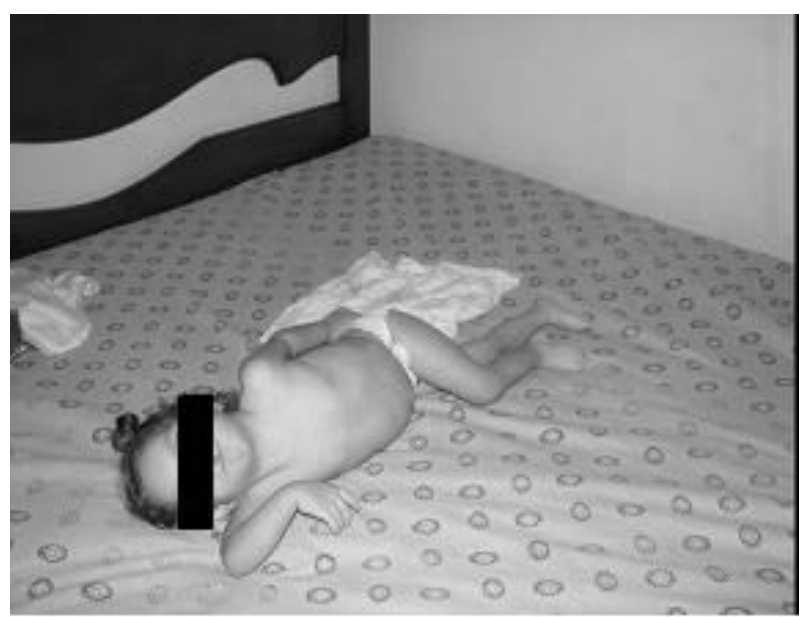

Fig: 03 - Posição Decúbito lateral

Puxado para Sentar: a cabeça se hiperestende, quando deveria fletir e encaixar o queixo Sentada: senta apenas com apoio, projeta o corpo para frente sem apoiar; apoia o tronco sobre os membros inferiores.

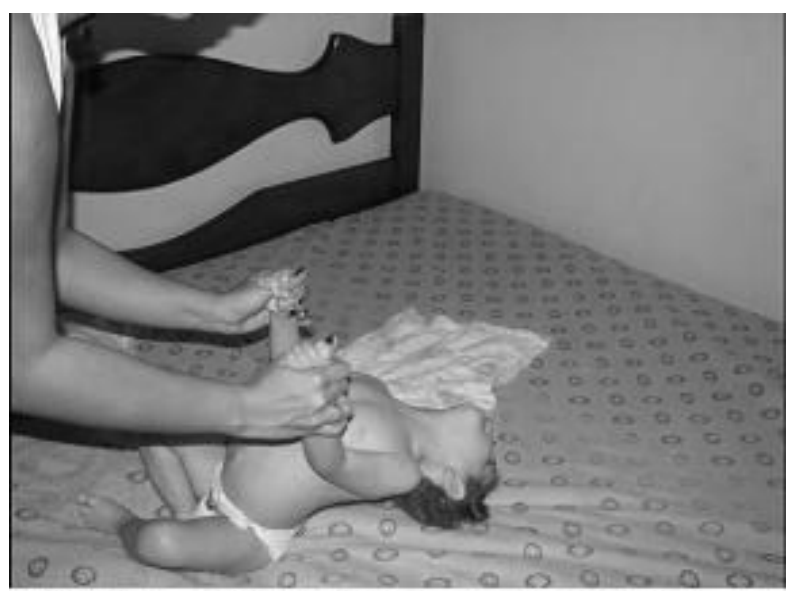

Fig: 04 - Posição Puxado para sentar e Sentada

De Pé: hiperestende a cabeça; não alinha o corpo; a coluna é cifótica; não estende quadril; tende a puxar o corpo para baixo; não apoia todo o pé e possui marcha ausente (presente até 15 meses).

Posição de Landau: ausência de extensão e alinhamento antigravitário; curva o corpo em forma de "U". Ao segurar a menina por baixo do tronco e mantê-la no ar, sua cabeça se flete para baixo e as pernas não sofrem extensão, ou seja, ela fica em formato de "U". 


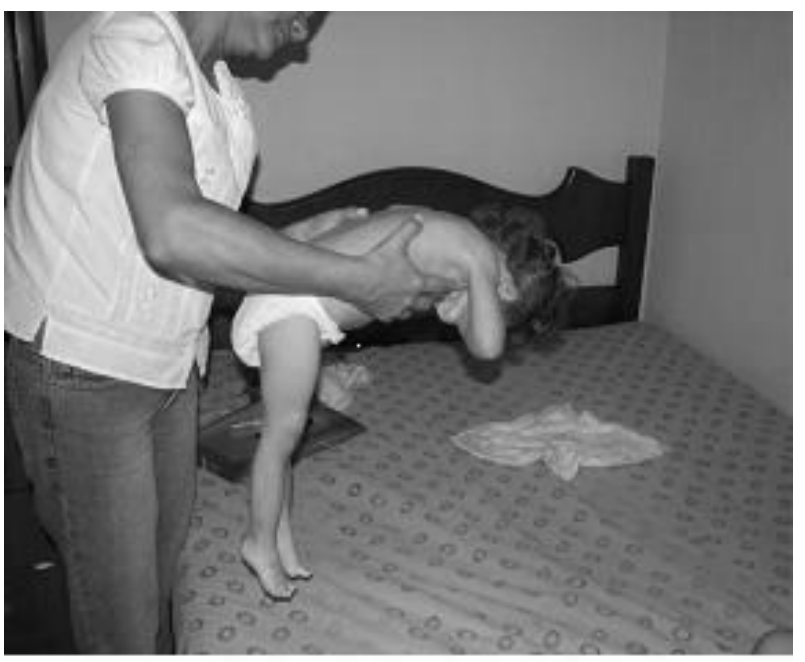

Fig: 05- Posição Landau e de Pé

Com relação à troca de posturas, ela não faz a troca de prono/gatas, prono/supino; não possui reação de proteção para frente. A ausência desta reação foi observada numa seção de fisioterapia: ao colocá-la sentada e empurrá-la para frente, observa-se que não apóia os braços para se proteger da superfície e não chora, mostrando que não se incomoda.

Nota-se então que, para a idade de 3 anos, a menina apresenta um significante atraso no desenvolvimento neuromotor, visto que ela não manifesta nenhuma reação e posição relacionada a sua idade.

\section{Mapa da Rede Social}

A construção do mapa da rede social baseou-se nos dados obtidos durante os encontros, o qual foi desenhado concentrando-se todas as relações positivas e negativas com familiares, vizinhos e instituições. Ressalta-se que a condição para a realização deste mapa dependeu do consenso e disponibilidade das pessoas envolvidas.

No primeiro momento foi pedido para a mãe descrever a história da criança e o cotidiano, o que gerou uma lista de nomes e serviços; foram registradas as palavras-chave e os termos mais utilizados; em seguida, foram trabalhadas as informações coletadas em notas e efetuada parcialmente uma análise de conteúdo até acrescentar uma análise final que emergiu de novos encontros ${ }^{1 .}$

Com isso, o desenho do mapa mostrou a representação de um momento determinado da história da menina. Ressalta-se que o mapa não é estático, uma vez que a realidade é dinâmica e mutável ${ }^{1}$

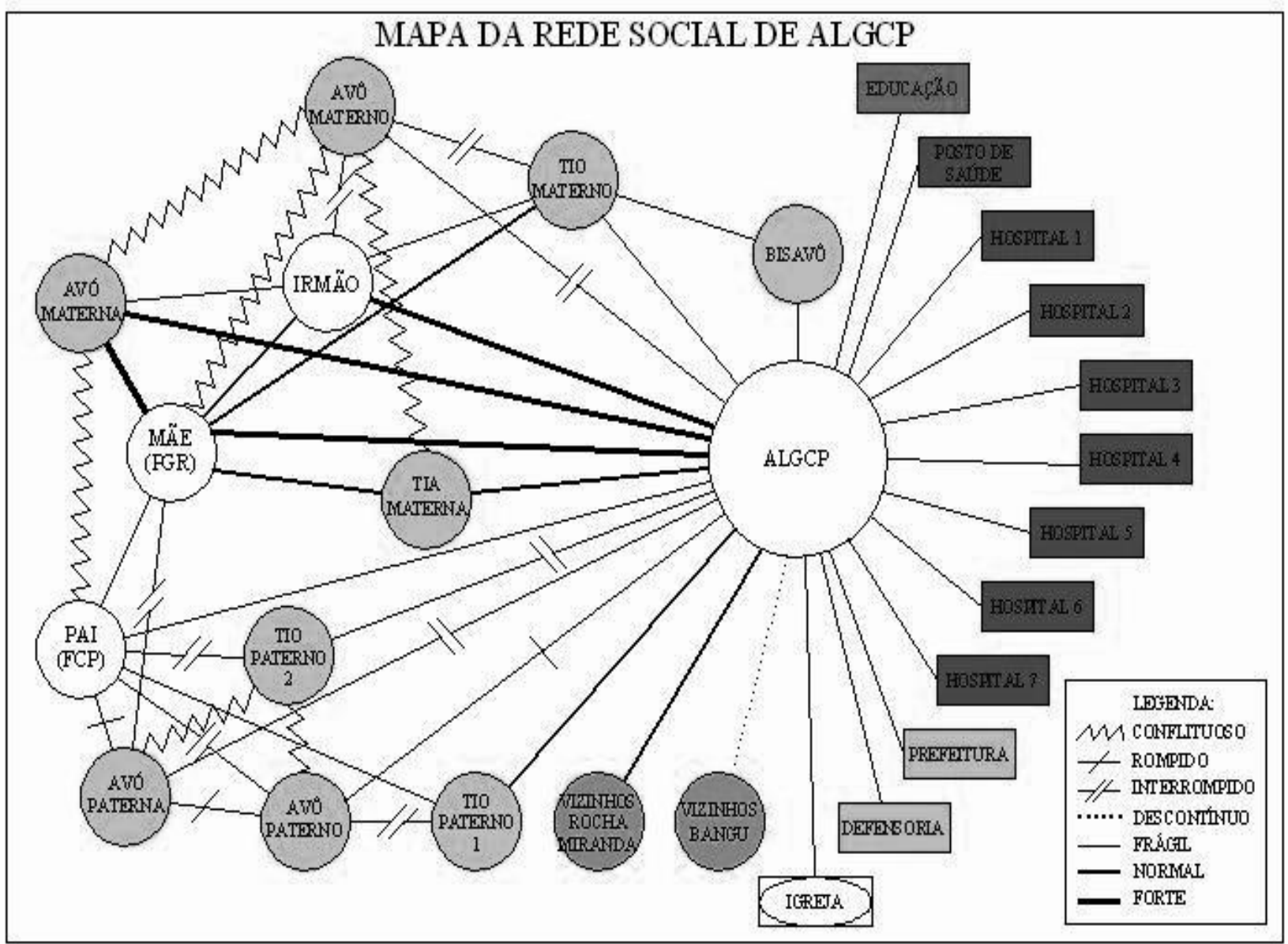


A.L.G.C.P. possui fortes vínculos com a mãe (P.G.R.), pelo cuidado intenso e integral, atenção, dedicação, amor, afeto e longa caminhada pelas especialidades médicas; isso pode ser visto no mapa através da linha mais grossa.

Mediante os relatos da mãe, percebe-se que a menina possui vínculo frágil com o pai (F.C.P); tal fato se traduz quando a mãe diz que o pai cuida pouco da menina e prefere ficar com ela quando a mãe está por perto. Esta representação gráfica é vista através da linha fina. Deve-se atentar para este vínculo, pois ele pode se interromper devido aos conflitos que os pais costumam ter. Para isso, é preciso intervenção que trabalhe com enfoque no vínculo pai-filha.

Com seu irmão (A.G.R), possui um vínculo forte representado por linha grossa no mapa, visto que o próprio menino cria esse vínculo mesmo em contato com ela apenas nos finais de semana, devido ao tempo que passa na casa da avó materna pela proximidade da escola. Este momento foi presenciado na visita domiciliar, quando ele brincava com ela $e$ ela respondia na tentativa de alcançar os objetos por ele oferecido.

0 vínculo de A.L.G.C.P e sua mãe com a avó paterna e o tio paterno de 21 anos se caracteriza como interrompido devido ao afastamento em relação à família, por pouco frequentarem a casa da criança; quando vão, apenas ficam na porta, criando uma barreira. Isso é mostrado no mapa pela linha seccionada no meio por dois traços. Em relação ao lado paterno de A.L.G.C.P., seu vínculo com a avó paterna é frágil, visto pela linha mais fina. Já com o avô paterno, a criança tem vínculo rompido, visto na linha seccionada com um traço no meio, pois não o conheceu em virtude dos laços interrompidos entre seu pai (F.C.R.) e ele.

Com o tio paterno de 7 anos ela possui vínculo normal, representado pela linha 1, que, em caso de descuido, pode passar por interrompido. Este apresenta essa característica, pois, nas poucas vezes que o tio consegue ter contato com a menina, ele a trata como se ela entendesse tudo e tem muito carinho por ela.

A.L.G.C.P. ainda tem vínculo forte, visto na linha grossa no mapa, com a avó materna, na casa da qual fica quando necessário. Este vínculo é observado através de relatos da mãe ao dizer que, quando a menina está agitada, o colo da avó sempre a satisfaz e logo a filha se acalma. Talvez esse vínculo só não seja mais forte por causa de um tio que a menina tem, de 20 anos, ao qual a avó materna precisa dedicar-se intensamente, da mesma forma que a sua filha (P.G.R.) se dedica a sua neta (A.L.G.C.P.). Com esse tio, o vínculo é frágil, isso devido às dificuldades de comunicação entre os dois por conta da disfunção neuromotora que ambos apresentam.

A respeito do avô materno, o vínculo é interrompido devido ao abandono da família. Esse avô conhece a neta, porém não dá nenhum suporte tanto a ela quanto à família. Separou-se da avó da menina e não presta assistência ao seu filho com necessidades especiais. Sendo assim, como ilustrado no mapa na linha sinuosa, o seu vínculo com a avó materna, a mãe e a tia materna da menina é conflituoso.

Além desse tio por parte de mãe, ainda existe uma tia que é casada e tem melhores condições de vida, e que, quando está ao lado da sobrinha, demonstra afeto e atenção. Segundo P.G.R., esta ajuda sempre que pode, comprando o necessário, como fraldas e leite. Por isso, este vínculo pode ser caracterizado como normal.

Ainda por parte da mãe, a criança tem um bisavô com o qual possui vínculo frágil devido à condição de saúde. Durante a visita domiciliar, este se mostrou um pouco indiferente ao que acontecia. Segundo relato da avó da menina, este avô contribui com sua aposentadoria para o neto (tio da menina) e a bisneta (A.L.G.C.P.).

Com relação aos vizinhos de Bangu, o contato ainda é pouco e o vínculo descontínuo, pelo momento de ambientação. Quanto ao local onde a avó materna mora, existe um vínculo normal com os vizinhos, tanto pelo tempo que ali moram quanto pela disponibilidade de ajuda que os mesmos oferecem.

A.L.G.C.P contata-se com uma rede secundária que se constitui de diferentes instituições necessárias para auxiliar a mãe em sua reabilitação. Destas instituições, fazem parte: Hospital 1) frequenta o setor de genética para estudo de uma possível síndrome, porém ainda com resultado negativo; Hospital 2) consulta na Neurologia e Fonoaudiologia voltada para deglutição, e ainda se vacina; Hospital 3) consulta com Gastrologia; Hospital 4) consulta de Enfermagem e Fisioterapia; Hospital 5) Fonoaudiologia voltada para fala; Hospital 6) Audiometria; Projeto Pró-Criança Cardíaca-Hospital 7) frequenta de 6 em 6 meses para o acompanhamento cardíaco; neste local recebe roupa e cesta básica, exceto leite porque não tem o de soja.

Ainda como rede secundária, a menina tem ainda a Defensoria Pública e a Prefeitura Municipal do Rio de Janeiro, classificadas como redes secundárias formais, pois a esses locais a mãe recorre pelos direitos da menina, como leite e fralda, visto que o "Rio Card" ela já possui. Dentro dessa rede, ainda há um Posto de Saúde em Irajá (Instituição de Saúde), onde a mãe da menina pega o leite de soja.

A mãe relata que a fisioterapia do Hospital Escola São Francisco de Assis/Hesfa encaminhou a menina para o Pólo Bebê mais próximo de sua residência, onde começará a estudar. Desta forma, pode-se considerar como rede secundária formal à instituição de educação a qual ela fará parte.

A menina ainda faz parte de uma rede secundária informal, por frequentar a lgreja com a mãe. Diz que, ao precisar de ajuda, recorre à lgreja. Por isso, há um vínculo entre a menina e a lgreja, onde existe uma troca de solidariedade. 


\section{CONSIDERAÇÕES FINAIS}

0 mapa da rede de A.L.G.C.P. é amplo, pois apresenta um número de pessoas vinculadas bastante significante (rede primária); possui um grande número de pessoas que se conhecem, o que permite visualizar quantos laços existem entre os membros da rede e verificar as inter-relações, classificandose assim como rede densa. Porém essa rede é marcada por relações frágeis, interrompidas, rompidas, normais e conflituosas, mostrando que há uma dificuldade nos relacionamentos pessoais e poucos vínculos fortes. Além disso, essa rede é composta por uma variedade de instituições, que auxiliam no caminho percorrido com objetivo de adequar, qualificar a reabilitação da criança e permitir a inclusão e direitos sociais dessa criança.

Após a descrição e o desenho do mapa da rede social da criança, pode-se dizer que, com relação às funções que seus membros exercem no relacionamento, incluem-se o suporte afetivo, material e informativo; a troca de direito, a reciprocidade; o efeito psicológico, que inclui a ajuda das equipes multidisciplinares, familiares com vínculos forte e normal; e a temporalidade, que se traduz na ajuda imediata ou a longo prazo, que é o caso da defensoria pública.

Desta forma, pode-se dizer que, apesar de a rede social ser uma rede ampla e densa, seus vínculos são fragilizados, o que torna a relação íntima e direta da menina restrita a poucas pessoas, como mãe, irmão e avó materna.

Sendo assim, para favorecer a rede social, o conhecimento das Políticas Públicas destinadas à assistência a pessoas portadoras de necessidades especiais, bem como da luta incessante de determinados grupos sociais de apoio em defender os direitos dessas pessoas, confere à Enfermagem a

\section{REFERÊNCIAS}

1- Soares MLPV. Vencendo a desnutrição: abordagem social. $1^{\mathrm{a}}$ ed. São Paulo (SP): Salus Paulista; 2002.

2- Camargo S, Souza B. Manual de ajuda para pais de crianças com paralisia cerebral. $1^{\text {a }}$ ed. São Paulo (SP): Pensamento; 1995.

3- Whaley LF, Wong DL. Enfermagem pediátrica: elementos essenciais à intervenção efetiva. $5^{\mathrm{a}}$ ed. Rio de Janeiro (RJ): Guanabara Koogan; 1999.

4- Agostini CL, Furtado K, Minguetti G. Tomografia computadorizada na agenesia do corpo caloso: Achados em 27 casos. Arq NeuroPsiquiatr 1998 set; 56(3-B): 601-04.

5 -Rede Sarah de Hospitais de Reabilitação. Doenças tratadas. Paralisia cerebral. Disponível em: www.sarah.br.

6- Wolff LMG, Santos TMM. Agenesia do corpo caloso: uma perspectiva de avaliação audiológica- estudo de caso. Rev CEFAC: Centro de Especialização em Fonoaudiologia Clínica. São Paulo (SP) 1999; 1(1): 26- 30.

7- Araruna RC, Vendrúscolo DMS. Alimentação da criança com fissura de lábio e/ ou palato: um estudo bibliográfico. Rev Latino-am Enfermagem $2000 \mathrm{abr} ; 8(2)$ : 99-105. responsabilidade de auxiliar na reeducação da sociedade em considerar esta clientela um membro integrante dela. Desta forma, tornam-se livres do estigma que as assolam e da marginalização que prejudica as relações interpessoais, a inserção no mercado de trabalho e o acesso à educação, cultura e lazer, e que as impedem de gozar plenamente do direito à igualdade social.

Esse processo pelo qual a sociedade se adapta para poder incluir em seu contexto as pessoas com necessidades especiais é denominado inclusão ${ }^{9}$. Segundo esta proposta, as pessoas com necessidades especiais precisam ser preparadas para assumir seus papéis como cidadãos. Para isso, faz-se necessária uma parceria - sociedade e pessoas especiais, com o objetivo de implementar a inclusão de forma adequada, qualificada $\mathrm{e}$ livre de preconceitos.

0 portador de necessidades especiais, de qualquer natureza, causa ou grau, é beneficiário do processo de reabilitação, considerado um processo de duração limitada e com objetivo definido, destinado a permitir que a pessoa alcance o nível físico, mental ou social funcional ideal, proporcionando-lhe os meios de modificar sua própria vida, podendo compreender medidas que visam a compensar a perda de uma função ou uma limitação funcional e facilitar ajustes ou reajustes sociais. 0 estudo contribuiu para a familia, tendo em vista o esclarecimento de dúvidas, de um modo geral, na tentativa de atender as necessidades da família/criança.

Para a Enfermagem/pesquisa, aumentou o número de estudos, em especial estudo de caso, na literatura, pois durante a revisão bibliográfica percebi a carência de publicações acerca da Enfermagem atuando com a criança com disfunção neuromotora.

8- Lei $n^{0} 7853$ de 24 de outubro de 1989. Dispõe sobre o apoio às pessoas portadoras de deficiência, sua integração social, sobre a Coordenadoria Nacional para Integração da Pessoa Portadora de Deficiência (CORDE), institui a tutela jurisdicional de interesses coletivos ou difusos dessas pessoas, disciplina a atuação do Ministério Público, define crimes, e dá outras providências. Disponível em http:// www.faders.rs.gov.br/legislacao .

9- Sassaki RK. Como promover a inclusão social. Disponível em http://www.aracaju.se.gov.br/crianca/artigos9.asp. 